\title{
Effect of temperature variation on microstrip patch antenna and temperature compensation technique
}

\author{
Sarita Maurya ${ }^{1}$, R. L. Yadava ${ }^{1}$, R. K. Yadav $^{2}$ \\ ${ }^{1}$ Department of Electronics \& Communication Engineering, Galgotia's College of Engineering and Technology, Greater Noida, India \\ ${ }^{2}$ Department of Electronics \& Communication Engineering, I.T.S Engineering College, Greater Noida, India
}

Email address:

sarita8815@gmail.com(S. Maurya), rly1972@gmail.com(R. L. Yadava), ravipusad@gmail.com(R. K. Yadav)

\section{To cite this article:}

Sarita Maurya, R. L. Yadava, R. K. Yadav. Effect of Temperature Variation on Microstrip Patch Antenna and Temperature Compensation Technique. International Journal of Wireless Communications and Mobile Computing. Vol. 1, No. 1, 2013, pp. 35-40.

doi: 10.11648/j.wcmc.20130101.16

\begin{abstract}
This paper describes the effect of temperature variation on microstrip patch antenna for different substrate materials. Eight materials are chosen as substrate and the effect of temperature variation is studied on each substrate material. A technique of temperature compensation has also been developed with substrate height variation. It is also seen that the change in resonance frequency due to variation of temperature can be compensated by varying the height of the substrate. The proposed antenna is designed and simulated by using HFSS software.
\end{abstract}

Keywords: Microstrip Patch Antenna, Substrate Material, Temperature Variations, Compensation

\section{Introduction}

The microstrip patch antenna has number of advantages over conventional antennas, such as low profile, light weight and low production cost. For better antenna performance, a thick dielectric substrate having a low dielectric constant is more desirable since this provides better efficiency, larger bandwidth, and better radiation [1]. It is well known that antenna is a very important component of a communication system.

One of the most important requirements for an antenna is to provide the stability of antenna parameters under meteorological factors alteration, in particular, under temperature conditions change. During a year the environment temperature depending on the geographical position can vary in the range from $-50^{\circ} \mathrm{C}$ to $+50^{\circ} \mathrm{C}$. Under the influence of solar radiation or other factors the top limit for the antenna heating temperature can reach a much larger values [2]. In some applications, a microstrip antenna is required to operate in an environment that is close to what is defined as a room or standard conditions. However, antennas often have to work in harsh environments characterized by temperature variations. In this case, the substrate properties suffer from some variations [3]. Antenna ground plane performance depends on its temperature, humidity and conductivity. Antenna temperature and the temperature of its environment correlate to radiation resistance. According to
"Antenna and Wave Propagation", the noise temperature of a lossless antenna is equal to the sky temperature and not the physical temperature. Higher temperatures equal a higher radiation resistance. This increases the signal loss of the antenna and interferes with the performance of the ground plane. The effect of that variation on the overall performance of a microstrip conformal antenna is very important to study under a wide range of temperature. For a microstrip antenna fixed on a projectile that fly at a long distance, the temperature will be an issue for the performance of that antenna. The temperature affects the dielectric constant of the substrate and also affects expansion of the material which increase or decrease the volume of the dielectric with increasing or decreasing the temperature. As the temperature increases, the effective dielectric constant is also increases for different materials used. On the other hand, the resonance frequency decreases with increasing temperature, while VSWR and return loss decreases as the temperature increases [4]. In this paper, a microstrip patch antenna operating at $3 \mathrm{GHz}$ frequency is designed simulated and the effect of temperature variation on eight substrate materials (GaAs, FR4, Quartz, Polyimide and polyethylene, Rogers, Neltec, Teflon) is analyzed. A method of temperature compensation is presented with the increased height of the substrate. The effects of temperature changes on the performances; resonance frequency, input impedance, voltage standing wave ratio, and return loss of microstrip patch antenna have also been presented. 


\section{Temperature Sensitivity of RMSA}

The resonant frequency of a MSA is sensitive to temperature variations. There are two major factors affecting the resonant frequency of a microstrip antenna exposed to large temperature variations [5]. The metallic expansion or contraction of the radiating patch due to a change in temperature affects the resonant frequency. With an increase in temperature, the metallic patch expands, making the effective resonant dimension longer and, therefore, decreasing the operating frequency. The relative frequency change for dimensional changes may be expressed in terms of linear dimensions or in terms of temperature changes. Most of the substrates which are generally used for microwave applications like Polytetra Fluroethylene (PTFE) based materials, Teflon/Fiberglass reinforced materials, and ceramic powder filled TFE (epsilon) materials exhibit a decrease in dielectric constant with an increase in temperature [6].

\section{Design Procedure of Antenna}

\subsection{Antenna Design Specifications}

The rectangular microstrip patch antenna has been designed by following procedure which assumes that the specified information includes;

- Resonant frequency $\left(f_{r}\right): 3 \mathrm{GHz}$

- Substrate thickness $(h): 1.6 \mathrm{~mm}$.

- Material used for patch and ground plane: Copper.

- Material used for dielectric substrate: GaAs, FR4, Quartz, Polyimide, Neltech, polyethylene, Rogers and Teflon.

- Substrate permittivity $\left(\varepsilon_{\mathrm{r}}\right): 12.9,4.4,3.78,3.5,2.6$, $2.25,2.17$ and 2.1 respectively.

The design of the whole structure of microstrip antenna is explained below:

- Initially, select the desired resonant frequency of operation, height of substrate and dielectric constant of the substrate.

- Obtain width $(W)$ of the patch.

- Obtain Length $(L)$ of the patch after determining the Length Extension $(\Delta L)$ and Effective dielectric constant $\left(\varepsilon_{e f f}\right)$ using following expressions; [7] \& [8].

$$
\begin{gathered}
W=\frac{\lambda}{2}\left(\frac{\varepsilon_{r}}{2}\right)^{-1 / 2} \\
L=\frac{1}{2 f_{r} \sqrt{\varepsilon_{e f f}} \sqrt{\mu_{0} \varepsilon_{0}}}-2 \Delta L
\end{gathered}
$$

Where

$$
\Delta L=0.412 h \frac{\left(\varepsilon_{e f f}+0.3\right)}{\left(\varepsilon_{e f f}+0.258\right)} \frac{\frac{W}{h}+0.264}{\frac{W}{h}+0.8}
$$

$$
\begin{gathered}
\varepsilon_{\text {eff }}=\frac{\left(\varepsilon_{\mathrm{r}}+1\right)}{2} \frac{\left(\varepsilon_{\mathrm{r}}-1\right)}{2} \frac{1}{\left(1+12 \frac{\mathrm{h}}{\mathrm{W}}\right)^{\frac{1}{2}}} \\
\frac{\Delta l_{t h}}{l}=7.2 \times 10^{-8} T^{3}+3.5 \times 10^{-8} T^{2}+0.013 T-0.26
\end{gathered}
$$

The relationship between temperature and $\varepsilon_{\mathrm{r}}$ is given by

$$
\varepsilon_{r}=0.00072 T+\varepsilon_{r}\left(a t T=27^{\circ} C\right)
$$

As a result new length/width of the microstrip antenna will be calculated by

$$
l=l_{0}+\Delta l_{\text {fringing }}+\Delta l_{\text {thermal }}
$$

\section{Simulation Environment}

The software used to model and simulate the microstrip patch antenna is High Frequency Structure Simulator (HFSS) software. HFSS is a high-performance full-wave electromagnetic (EM) field simulator for arbitrary 3D volumetric passive device modeling. Ansoft HFSS employs the Finite Element Method (FEM), adaptive meshing, and brilliant graphics to give unparalleled performance and insight to all 3D EM problems. Ansoft HFSS can be used to calculate parameters such as $\mathrm{S}$ parameters, resonant frequency, and fields.

The length and the width of the patch and the ground plane found to be: $L=30.4 \mathrm{~mm}, W=24.16 \mathrm{~mm}, L_{g}=90 \mathrm{~mm}$, $W_{g}=76 \mathrm{~mm}$.

\section{Patch Antenna without Temperature Variation: Simulation Results}

The rectangular microstrip patch antenna is designed for the mentioned antenna specifications and also simulated for the substrate materials. Without any Temperature variation the simulation results for eight substrate material are given in Tables 1 and 2.

Table 1. List of materials used with their dielectric constant, resonant frequency and return loss

\begin{tabular}{ccccc}
\hline \multicolumn{5}{c}{ Without temperature variation } \\
\hline S.No. & $\begin{array}{c}\text { Name of } \\
\text { material }\end{array}$ & $\begin{array}{c}\text { Dielectric } \\
\text { constant } \\
\left(\boldsymbol{\varepsilon}_{\mathrm{r}}\right)\end{array}$ & $\begin{array}{c}\text { Resonant } \\
\text { frequency } \\
(\mathbf{G H z})\end{array}$ & $\begin{array}{c}\text { Return loss } \\
(\mathbf{d B})\end{array}$ \\
\hline 1 & GaAs & 12.9 & 1.671119 & -13.4131 \\
2 & FR4 & 4.4 & 2.823873 & -16.8336 \\
3 & Quartz & 3.78 & 3.030467 & -14.2122 \\
4 & Polyimide & 3.5 & 3.151085 & -11.6956 \\
5 & Neltec & 2.6 & 3.616027 & -12.4734 \\
6 & Polyethylene & 2.25 & 3.802671 & -13.7565 \\
7 & Rogers & 2.17 & 3.850083 & -14.7122 \\
8 & Teflon & 2.1 & 4.010851 & -14.0404 \\
\hline
\end{tabular}


Table 2. List of materials used with their dielectric constant, VSWR and Gain

\begin{tabular}{clccc}
\hline $\begin{array}{c}\text { S. } \\
\text { No. }\end{array}$ & $\begin{array}{c}\text { Name of } \\
\text { material }\end{array}$ & $\begin{array}{c}\text { Dielectric } \\
\text { constant } \\
(\mathbf{( r )})\end{array}$ & VSWR & $\begin{array}{c}\text { Gain } \\
(\mathbf{d B})\end{array}$ \\
\hline 1 & GaAs & 12.9 & 1.542828 & 3.51 \\
2 & FR4 & 4.4 & 1.336412 & 4.19 \\
3 & Quartz & 3.78 & 1.483581 & 7.36 \\
4 & Polyimide & 3.5 & 1.703245 & 5.99 \\
5 & Neltec & 2.6 & 1.624204 & 6.27 \\
6 & Polyethylene & 2.25 & 1.51635 & 5.31 \\
7 & Rogers & 2.17 & 1.450435 & 5.76 \\
8 & Teflon & 2.1 & 1.495633 & 5.40 \\
\hline
\end{tabular}

\section{Patch Antenna with Temperature Variation: Simulated Results}

The results of four materials for variation of temperature from $270 \mathrm{C}$ to $1170 \mathrm{C}$ are discussed below with their graphs between resonance frequencies vs. return loss. Here, the effect of temperature variation on dielectric constant, resonant frequency and return loss is discussed. The results for another four materials are same. The results tabulated in table 3 are obtained by variation of temperature:

Case (1): Variation of temperature on the antenna for material (M1): FR4 $(\varepsilon r=4.4)$

In case $(1)$, the dielectric material FR4 $(\varepsilon r=4.4)$ has been considered for designing of the antenna, and simulated results are represented in Figure (1) and Table 3. Figure (1) shows that the first curve of resonant frequency is the actual resonant frequency of the antenna without temperature variation.

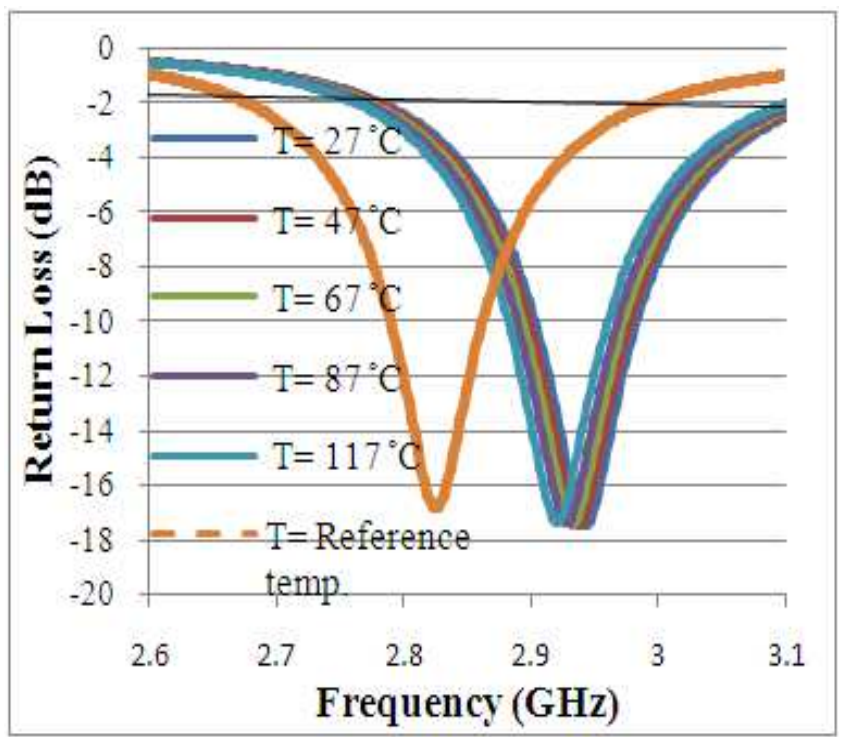

Figure 1. Return loss at various temperature of the antenna for FR4 substrate

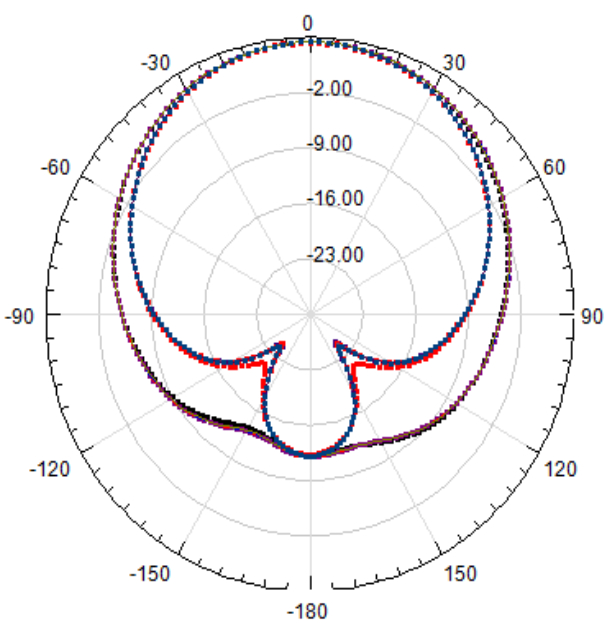

Figure 2. Gain of FR4 at various temperatures

Table 3. Effect of temperature variation on FR4

\begin{tabular}{ccccccc}
\hline $\begin{array}{c}\text { S. } \\
\text { No. }\end{array}$ & $\begin{array}{c}\text { Temperature } \\
\left({ }^{\mathbf{0}} \mathbf{C}\right)\end{array}$ & $\boldsymbol{\varepsilon}_{\mathbf{r t}}$ & $\begin{array}{c}\mathbf{f}_{\mathbf{r}} \\
(\mathbf{G H z})\end{array}$ & $\mathbf{S}_{\mathbf{1 1}}$ & VSWR & $\begin{array}{l}\text { Gain } \\
(\mathbf{d B})\end{array}$ \\
\hline 1. & 27 & 4.0506 & 2.9415 & -17.503 & 2.329 & 4.40 \\
2. & 47 & 4.0650 & 2.9365 & -17.471 & 2.338 & 4.41 \\
3. & 67 & 4.0794 & 2.9315 & -17.439 & 3.469 & 4.40 \\
4. & 87 & 4.0938 & 2.9265 & -17.407 & 2.355 & 4.39 \\
5. & 117 & 4.1154 & 2.9190 & -17.357 & 2.369 & 4.38 \\
\hline
\end{tabular}

It is clear that on increasing the temperature the value of dielectric constant of substrate material increases and resonant frequency decreases. Decrease in resonance frequency led to the increase in return losses. The actual resonance frequency of FR4 material without any temperature variation is $2.823873 \mathrm{GHz}$, return loss of -16.8336 and VSWR of 1.336412 . It is also clear that on increasing the temperature the resonant frequency decreases towards the value of actual resonant frequency. Figure (2) shows the gain of antenna for FR4 substrate from temperature $27{ }^{0} \mathrm{C}$ to $117{ }^{\circ} \mathrm{C}$. The gain of antenna is not much affected by temperature variation.

Case 2: Variation of Temperature on the antenna for material $\left(\mathrm{M}_{2}\right)$ : Quartz $\left(\varepsilon_{\mathrm{r}}=3.78\right)$

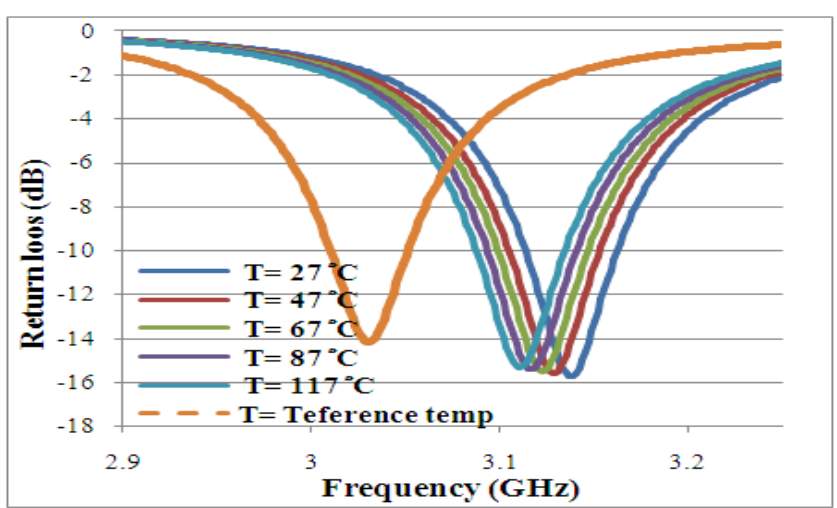

Figure 3. Return-loss of various temperature of the antenna for Quartz substrate 


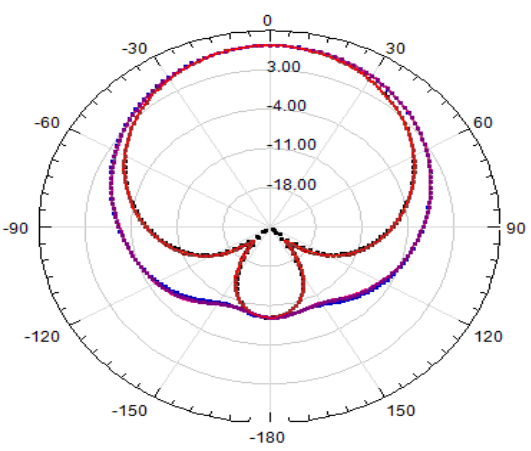

Figure 4. Gain of Quartz at various temperatures

Table 4. Effect of temperature variation on Quartz

\begin{tabular}{ccccccc}
\hline $\begin{array}{c}\text { S. } \\
\text { No. }\end{array}$ & $\begin{array}{c}\text { Temperature } \\
\left({ }^{\mathbf{0}} \mathbf{C}\right)\end{array}$ & $\boldsymbol{\varepsilon}_{\mathbf{r t}}$ & $\begin{array}{c}\mathbf{f r} \\
(\mathbf{G H z})\end{array}$ & $\mathbf{S}_{\mathbf{1 1}}$ & VSWR & $\begin{array}{c}\text { Gain } \\
(\mathbf{d B})\end{array}$ \\
\hline 1. & 27 & 3.5105 & 3.1373 & -15.750 & 1.389 & 7.30 \\
2. & 47 & 3.5249 & 3.1298 & -15.634 & 1.396 & 7.31 \\
3. & 67 & 3.5393 & 3.1261 & -15.577 & 1.402 & 7.31 \\
4. & 87 & 3.5537 & 3.1183 & -15.461 & 1.407 & 7.32 \\
5. & 117 & 3.5753 & 3.1106 & -15.345 & 1.412 & 7.32 \\
\hline
\end{tabular}

In case 2 , the dielectric material Quartz $(\varepsilon r=3.78)$ has been considered for designing of the antenna, and simulated results are represented in Figure (3) and Table 4. Figure (3) shows that the first curve of resonant frequency is the actual resonant frequency of the antenna without temperature variation. It is clear that on increasing the temperature the value of dielectric constant of substrate material increases and resonant frequency decreases. Decrease in resonance frequency led to the increase in return losses. The actual resonance frequency of Quartz material without any temperature variation is 3.030467 $\mathrm{GHz}$, return loss of -14.2122 and VSWR is of 1.483581. It is also clear that on increasing the temperature the resonant frequency decreases towards the value of actual resonant frequency. Figure 4 shows the gain of antenna for Quartz substrate from temperature $270 \mathrm{C}$ to $1170 \mathrm{C}$. The gain of antenna is not much affected by temperature variation.

Case 3: Variation of Temperature on the antenna for material (M3): Polyimide $(\varepsilon r=3.5)$

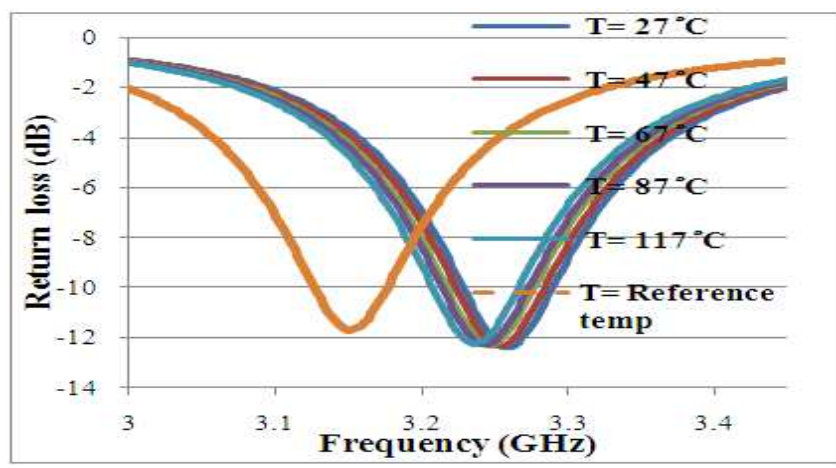

Figure 5. Graph of Frequency (GHz) vs. Return Losses of Polyimide

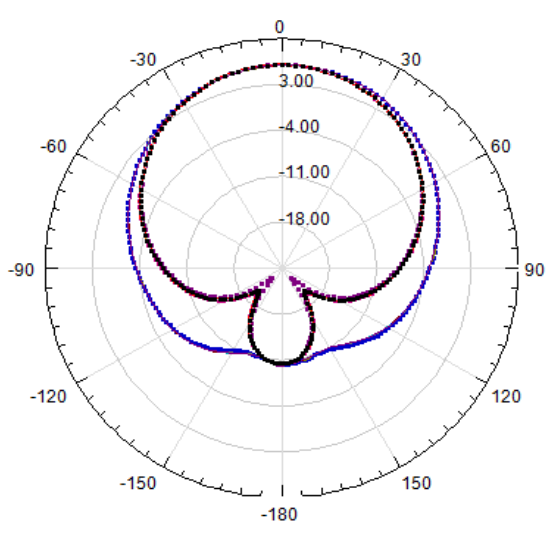

Figure 6. Gain of Polyimide at various temperatures

Table 5. Effect of temperature variation on Polyimide

\begin{tabular}{ccccccc}
\hline $\begin{array}{c}\text { S. } \\
\text { No. }\end{array}$ & $\begin{array}{c}\text { Temperature } \\
\left({ }^{\mathbf{0}} \mathbf{C}\right)\end{array}$ & $\boldsymbol{\varepsilon}_{\mathbf{r t}}$ & $\begin{array}{c}\mathbf{f r} \\
\mathbf{( G H z )}\end{array}$ & $\mathbf{S}_{\mathbf{1 1}}$ & VSWR & $\begin{array}{c}\text { Gain } \\
(\mathbf{d B})\end{array}$ \\
\hline 1. & 27 & 3.2651 & 3.2587 & -12.390 & 1.632 & 5.94 \\
2. & 47 & 3.2795 & 3.2537 & -12.357 & 1.635 & 5.95 \\
3. & 67 & 3.2939 & 3.2462 & -12.312 & 1.639 & 5.96 \\
4. & 87 & 3.3083 & 3.2412 & -12.265 & 1.641 & 5.97 \\
5. & 117 & 3.3299 & 3.2312 & -12.202 & 1.645 & 5.97 \\
\hline
\end{tabular}

In case 3 , the dielectric material Polyimide $(\varepsilon r=3.5)$ has been considered for designing of the antenna, and simulated results are represented in Figure (5) and Table 5. Figure (5) shows the first curve of actual resonance frequency of the antenna without temperature variation. The variation is found to be same as in previous case. The actual resonance frequency of Polyimide material without any temperature variation is $3.151085 \mathrm{GHz}$, return loss= -11.6956 and $\mathrm{VSWR}=1.703245$. Figure (6) shows the gain of antenna for Polyimide substrate from temperature $270 \mathrm{C}$ to $1170 \mathrm{C}$. The gain of antenna is not much affected by temperature variation.

Case 4: Variation of Temperature on the antenna for material (M4): Teflon $(\varepsilon r=2.1)$

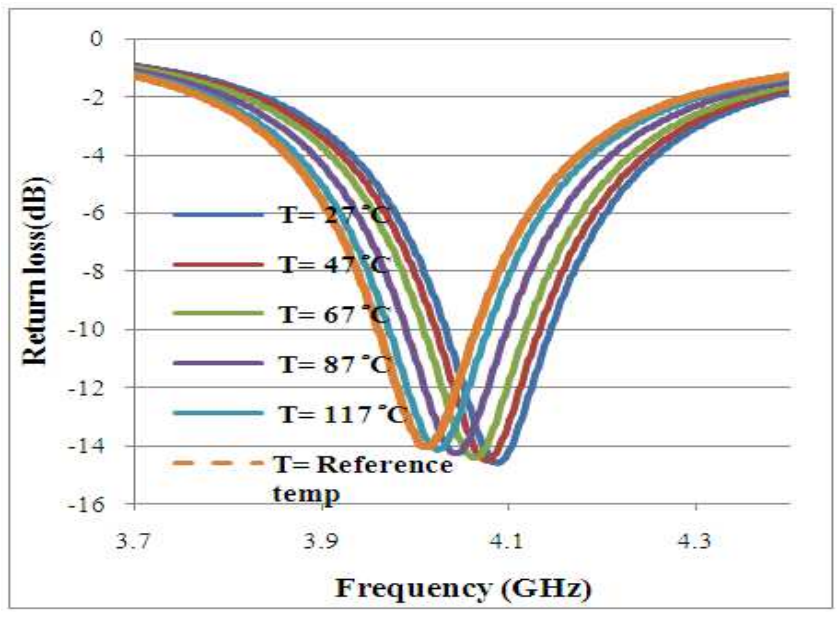

Figure 7. Return loss of various temperature of the antenna for Teflon substrate 
In case 4 , the dielectric material Teflon $\left(\varepsilon_{\mathrm{r}}=2.1\right)$ has been considered for designing of the antenna, and simulated results are represented in figure (7) and Table 6 and as usual variations have been noticed.

The results for other four materials are also same.

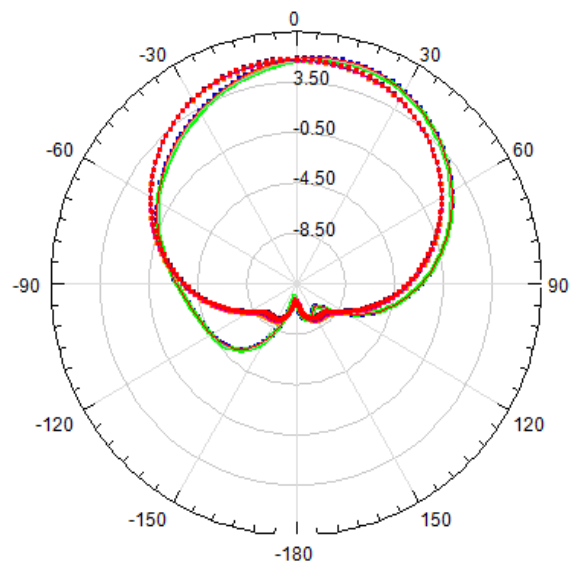

Figure 8. Gain of Teflon at various temperatures

Table 6. Effect of temperature variation on Teflon material

\begin{tabular}{ccccccc}
\hline $\begin{array}{c}\text { S. } \\
\text { No. }\end{array}$ & $\begin{array}{c}\text { Temperature } \\
\left({ }^{\mathbf{0}} \mathbf{C}\right)\end{array}$ & $\boldsymbol{\varepsilon}_{\mathbf{r t}}$ & $\begin{array}{c}\mathbf{f r} \\
(\mathbf{G H z})\end{array}$ & $\mathbf{S}_{\mathbf{1 1}}$ & VSWR & $\begin{array}{c}\text { Gain } \\
(\mathbf{d B})\end{array}$ \\
\hline 1. & 27 & 2.0218 & 4.0834 & -14.748 & 1.458 & 5.19 \\
2. & 47 & 2.0362 & 4.0734 & -14.488 & 1.463 & 5.20 \\
3. & 67 & 2.0506 & 4.0534 & -14.340 & 1.470 & 5.24 \\
4. & 87 & 2.0650 & 4.0434 & -14.270 & 1.479 & 5.31 \\
5. & 117 & 2.0866 & 4.0233 & -14.128 & 1.489 & 5.37 \\
\hline
\end{tabular}

\section{Temperature Compensation}

To compensate the decrease in resonance frequency due to variation of temperature, the height of substrate is increased. Here, the substrate height of four materials (FR4, Quartz, Polyimide and Teflon) has been varied. The formula used for Temperature Compensation with variation of height of substrates is as follows;

$$
h=\frac{W}{12}\left[\left(\frac{1}{\varepsilon_{e f f}} \frac{\left(\varepsilon_{r}+1\right)}{2} \frac{\left(\varepsilon_{r}-1\right)}{2}\right)^{2}-1\right]
$$

As the height of substrates is increased from its original value $(1.6 \mathrm{~mm})$, the dielectric constant decreases for FR4 and Quartz materials, hence, the resonance frequency decreases. But the dielectric constant increases for Polyimide and Teflon substrate and resonance frequency increases. In this way at a particular height of substrate for each material the actual resonance frequency is obtained. The results are tabulated in tables 7-10 are obtained with variation of height of the substrate for four materials:

\subsection{Temperature Compensation with variation of height of substrate of FR4}

Since, the original height of the substrate is $1.6 \mathrm{~mm}$. Here, the height of FR4 Substrate is increased from $1.6 \mathrm{~mm}$ to 4.0 and then to $4.8 \mathrm{~mm}$ and found that at $h=4.6 \mathrm{~mm}, \varepsilon_{r t}=$ 3.7976, $f r=2.823873 \mathrm{GHz}$. This is the actual resonance frequency of FR4 substrate material without temperature variation. This confirms that temperature compensation can be achieved by increasing the height of substrate material.

Table 7. Temperature compensation of FR4 material

\begin{tabular}{ccccc}
\hline $\begin{array}{c}\text { S. } \\
\text { No. }\end{array}$ & Height of Substrate(mm) & $\boldsymbol{\varepsilon}_{\mathrm{rt}}$ & $\begin{array}{c}\mathbf{f r} \\
(\mathbf{G H z})\end{array}$ & $\mathbf{S}_{\mathbf{1 1}}$ \\
\hline 1. & 4 & 3.8431 & 2.851419 & -23.8728 \\
2. & 4.5 & 3.8048 & 2.831386 & -17.2563 \\
3. & 4.6 & 3.7976 & 2.823873 & -16.5136 \\
4. & 4.7 & 3.7906 & 2.821369 & -15.6219 \\
5. & 4.8 & 3.7837 & 2.818865 & -14.8711 \\
\hline
\end{tabular}

\subsection{Temperature Compensation with Variation of Height} of Substrate of Quartz

Here, the height of Quartz Substrate is increased from $1.6 \mathrm{~mm}$ to $6.7 \mathrm{~mm}$ and found that at $h=6.6 \mathrm{~mm}, \varepsilon_{r t}=3.2227$, $f r=3.030467 \mathrm{GHz}$. This is the actual resonance frequency of Quartz substrate material without temperature variation.

Table 8. Temperature compensation of Quartz material

\begin{tabular}{lcccc}
\hline $\begin{array}{l}\text { S. } \\
\text { No. }\end{array}$ & Height of Substrate $(\mathbf{m m})$ & $\boldsymbol{\varepsilon}_{\mathbf{r t}}$ & $\begin{array}{c}\mathbf{f r} \\
(\mathbf{G H z})\end{array}$ & $\mathbf{S}_{\mathbf{1 1}}$ \\
\hline 1. & 5 & 3.2969 & 3.126461 & -18.4251 \\
2. & 6 & 3.2481 & 3.070952 & -27.1579 \\
3. & 6.5 & 3.2268 & 3.041736 & -18.4557 \\
4. & 6.6 & 3.2227 & 3.030467 & -17.5575 \\
5. & 6.7 & 3.2187 & 3.02379 & -16.6711 \\
\hline
\end{tabular}

\subsection{Temperature Compensation with Variation of Height of Substrate of Polyimide}

Here, the height of Polyimide Substrate is increased from $1.6 \mathrm{~mm}$ to $3.5 \mathrm{~mm}$ and then to $4 \mathrm{~mm}$ and found that at $h=3.73$ $\mathrm{mm}, \varepsilon_{r t}=3.1509, f_{r}=3.151085 \mathrm{GHz}$. This is the actual resonance frequency of Polyimide substrate material without temperature variation.

Table 9. Temperature compensation of polymide material

\begin{tabular}{ccccc}
\hline S.No. & $\begin{array}{c}\text { Height of } \\
\text { Substrate(mm) }\end{array}$ & $\boldsymbol{\varepsilon}_{\text {rt }}$ & $\begin{array}{c}\text { fr } \\
\text { (GHz) }\end{array}$ & S11 \\
\hline 1. & 3.5 & 3.1657 & 3.163606 & -38.0245 \\
2. & 3.7 & 3.1528 & 3.153589 & -26.7789 \\
3. & 3.72 & 3.1515 & 3.153589 & -26.3730 \\
4. & 3.73 & 3.1509 & 3.151085 & -25.8475 \\
5. & 4 & 3.1345 & 3.138564 & -20.3086 \\
\hline
\end{tabular}

\subsection{Temperature Compensation with Variation of Height of Substrate of Teflon}

Here, the height of Teflon Substrate is increased from 1.6 $\mathrm{mm}$ to $2 \mathrm{~mm}$ and then to $4 \mathrm{~mm}$ and also found that at $h=2.8$ $\mathrm{mm}, \varepsilon_{r t}=2.0401, f r=4.010851 \mathrm{GHz}$. This is the actual resonance frequency of Teflon substrate material without 
temperature variation.

Table 10. Temperature compensation of Teflon material

\begin{tabular}{ccccc}
\hline S.No. & Height of Substrate(mm) & $\boldsymbol{\varepsilon}_{\mathbf{r t}}$ & $\mathbf{f r}$ & $\mathbf{( G H z )}$ \\
\hline 1. & 2 & 2.0694 & 3.904508 & -12.8160 \\
2. & 2.5 & 2.0504 & 3.928548 & -13.1583 \\
3. & 2.8 & 2.0401 & 4.010851 & -11.2272 \\
4. & 3 & 2.0336 & 3.933222 & -19.1445 \\
5. & 4 & 2.0055 & 3.826377 & -21.1603 \\
\hline
\end{tabular}

The Tables 7, 8, 9, and 10 also shows that the decrease in resonance frequency due to variation of temperature can be compensated by increasing the height of the substrate. But the variation of height is different for each material.

\section{Conclusions}

In this paper, the rectangular microstrip patch antenna is designed and simulated with the temperature variation on different substrates materials suitable for wireless sensor network. The effect of temperature dependent of the substrate varies its dielectric constant and resonance frequency. Due to increase in temperature the dielectric constant of substrate material decreases from original dielectric constant of substrate because of this effect the resonance frequency increases from the value of operating frequency for all the substrate materials. For FR4 material, the actual resonance frequency without any temperature variation is $2.823873 \mathrm{GHz}$. After increasing the temperature up to $117^{\circ} \mathrm{C}$ the resonance frequency increases to $2.9190 \mathrm{GHz}$, Which is compensated by increasing the height of substrate material from $1.6 \mathrm{~mm}$ to $4.6 \mathrm{~mm}$. For Quartz material, the actual resonance frequency without any temperature variation is $3.030467 \mathrm{GHz}$. After increasing the temperature up to $1170 \mathrm{C}$ the resonance frequency increases to $3.1106 \mathrm{GHz}$, Which is compensated by increasing the height of substrate material from $1.6 \mathrm{~mm}$ to $6.6 \mathrm{~mm}$. For Polyimide material, the actual resonance frequency without any temperature variation is 3.151085 $\mathrm{GHz}$. After increasing the temperature up to $1170 \mathrm{C}$ the resonance frequency increases to $3.2312 \mathrm{GHz}$, which is compensated by increasing the height of substrate material from $1.6 \mathrm{~mm}$ to $3.73 \mathrm{~mm}$. For Teflon material, the actual resonance frequency without any temperature variation is 4.010851 GHz. After increasing the temperature up to 117 0C the resonance frequency increases to $4.0233 \mathrm{GHz}$, Which is compensated by increasing the height of substrate material from $1.6 \mathrm{~mm}$ to $2.8 \mathrm{~mm}$. Therefore, it has been concluded that the increase in resonant frequency due to temperature variation can be compensated by the variation of height of substrate material. It has been clear from the above analysis that if the temperature of environment changes (increases) the temperature compensation can be done by increasing the height of substrate material and microstrip patch antenna can be used in that environment successfully. Also the above substrate materials can be preferred for antenna designing in that environment where the temperature conditions changes considerably.

\section{References}

[1] M., Kumar, Sinha, M. K., Bandyopadhyay, L. K., \& Kumar, S. (n.d.). "Design of a Wideband Reduced Size Microstrip Antenna". In. Retrieved from Union Radio-Scientifique Intemationale.

[2] N. I .Voytovich, A. V. Ershov, V .A. Bukharin, N. N. Repin, "Temperature effect on cavity antenna parameters," General Assembly and Scientific Symposium, 2011 XXXth URSI , 13-20 Aug. 2011,pp-1-4.

[3] P. Kabacik, and M. Bialkowski, "The temperature dependence of substrate parameters and their effect on microstrip antenna performance," IEEE Trans. on Antennas and Propag., Vol. 47, No. 6,Jun. 1999, pp. 1042-1049.

[4] R. K. Yadav, J. Kishor and R. L. Yadava, "Effects of Temperature Variations on Performances of Microstrip Antenna", International Journal of Networks and Communication 2013, Vol.3, issue 1, pp.21,24.

[5] M. A. Weiss, "Temperature compensation of microstrip antennas," in IEEE Antennas Propagation Soc. Int. Symp. Dig., Losa Angeles, CA, June 1981, vol. 1, pp. 337-349.

[6] K. Carver, and J. Mink, "Microstrip antenna technology," IEEE Transaction on Antennas and Propagation, Vol. AP.29, No. 1, January 1981 ,pp.1-24.

[7] Md. M. Ahamed, etal. "Rectangular Microstrip Patch Antenna at $2 \mathrm{GHZ}$ on Different Dielectric Constant for Pervasive Wireless Communication". International Journal of Electrical and Computer Engineering (IJECE).Vol.2, No.3, June 2012, pp. 417 - 424.

[8] A. Elrashidi, K. Elleithy and H. Bajwa, "The performance of a cylindrical microstrip printed antenna for TM10 mode as a function of temperature for different substrates," International Journal of Next-Generation Networks (IJNGN), Vol.3, No.3, September 2011, pp.1-18.

[9] S. Babu and G. Kumar, "Parametric study and temperature sensitivity of microstrip antennas using an improved linear transmission line Model, " IEEE Transactions on Antennas and Propagation, Vol. 47, No. 2, pp.221-226, February 1999. 